\title{
Correction to: A Metamodel-Based Analysis of the Sensitivity and Uncertainty of the Response of Chesapeake Bay Salinity and Circulation to Projected Climate Change
}

\author{
Andrew C. Ross $^{1}$ (D) Raymond G. Najjar ${ }^{2} \cdot{\text { Ming } \mathrm{Li}^{3}}^{3}$ \\ Published online: 19 March 2021 \\ (C) Coastal and Estuarine Research Federation 2021
}

Correction to: Estuaries and Coasts (2021) 44:70-87 https://doi.org/10.1007/s12237-020-00761-w

The original online version of the article has been corrected. On page 77 , right column, first paragraph, the sentence is revised as follows:
Therefore, for a given factor, the first-order index gives the expected fraction by which the output variance would be reduced if the factor $i$ was exactly known, while the total index gives the fraction of variance that would remain if all factors except factor $i$ were known (Saltelli et al. 2010).

The online version of the original article can be found at https://doi.org/ 10.1007/s12237-020-00761-w

\footnotetext{
Andrew C. Ross

andrewross@princeton.edu

1 Princeton University Program in Atmospheric and Oceanic Sciences, Princeton, New Jersey, USA

2 Department of Meteorology and Atmospheric Science, The Pennsylvania State University, University Park, Pennsylvania, USA

3 University of Maryland Center for Environmental Science, Horn Point Lab, Cambridge, Maryland, USA
} 